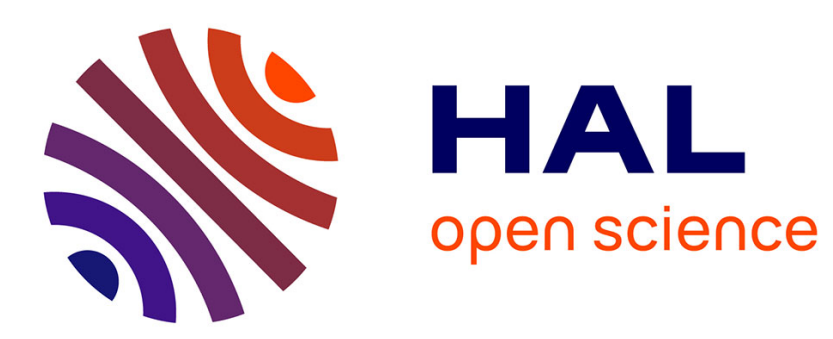

\title{
Modeling Emulsification in Static Mixers: Equilibrium Correlations versus Population Balance Equations
}

\author{
Noureddine Lebaz, Nida Sheibat-Othman
}

\section{To cite this version:}

Noureddine Lebaz, Nida Sheibat-Othman. Modeling Emulsification in Static Mixers: Equilibrium Correlations versus Population Balance Equations. Chemical Engineering and Technology, 2019, 42 (8), pp.1691-1701. 10.1002/ceat.201900109 . hal-02130395

\section{HAL Id: hal-02130395 https://hal.science/hal-02130395}

Submitted on 28 Nov 2020

HAL is a multi-disciplinary open access archive for the deposit and dissemination of scientific research documents, whether they are published or not. The documents may come from teaching and research institutions in France or abroad, or from public or private research centers.
L'archive ouverte pluridisciplinaire $\mathbf{H A L}$, est destinée au dépôt et à la diffusion de documents scientifiques de niveau recherche, publiés ou non, émanant des établissements d'enseignement et de recherche français ou étrangers, des laboratoires publics ou privés. 
Modeling emulsification in static mixers: equilibrium correlations versus population balance equations

Noureddine Lebaz ${ }^{1}$, Nida Sheibat-Othman ${ }^{1 *}$

${ }^{1}$ University of Lyon, Université Claude Bernard Lyon 1, CNRS, LAGEPP UMR 5007, F-69100, Villeurbanne, France

${ }^{*}$ Correspondence : Dr Nida Sheibat-Othman (E-mail : nida.othman@univ-lyon1.fr)

\section{Abstract}

Two different modeling approaches are adopted to model turbulent breakage during continuous emulsification in static mixers. First, a correlation is developed to predict the droplet mean diameter. Second, a population balance equation (PBE) is used to track the droplet size distribution (DSD) using two different breakage kernels. The performances of the two approaches are assessed against a large number of experimental data. The correlation is fast to develop and is found to be capable of predicting the mean diameter with an acceptable accuracy while the PBE-based model gives an excellent prediction of the entire DSD.

Keywords: turbulent emulsification, droplet breakage, population balance, static mixers, droplet size distribution

\section{Introduction}

Liquid-liquid dispersions are present in a large panel of consumable goods such as food, cosmetic and pharmaceutical products [1]. The formulation of emulsions with controlled droplet size distribution (DSD) is important since it affects the product quality, such as bioavailability or texture. The dispersion of the fluid requires energy dissipation. This can be achieved in batch processes such as stirred tanks, rotorstators, ultrasonication, high pressure homogenizers, or in continuous processes using static mixers or membranes.

Static mixers are motionless in-line mixing elements that generate turbulence due to their geometrical structure. They lead to an efficient homogenization with lower power compared to high pressure homogenizers. They offer other advantages like compactness, sharp residence time distribution, reduced maintenance requirements and enhanced safety [2].

An abundant literature is available regarding modeling emulsification in stirred tanks. First, equilibrium correlations were developed to relate the mean droplet size to the process parameters and the physicochemical properties of the two phases $[3,4]$. The main drawback of these correlations is their validity only at equilibrium and the prediction of the mean droplet size, which may not be sufficient to predict the end-use properties of the emulsion. The use of population balance equations (PBE) was therefore introduced to predict the evolution of the full DSD with time based on breakage and coalescence kernels. These kernels rely on the energy dissipation that is not uniform in most emulsification devises. To address this issue, coupling of PBE with computational fluid dynamics (CFD) was employed to allow for a 
detailed description of the time-space variations of the DSD, but such coupling is computationally heavy [5]. One of the advantages of static mixers is that they allow for a relatively uniform energy dissipation. Therefore, a fundamental prediction of the breakage and coalescence parameters becomes possible without a need of coupling with CFD.

The aim of this work is to compare the use of mean-size correlations and PBE to model emulsification in static mixers. While both approaches are used in the literature, they are rarely compared in the same paper. Mean-size correlations have the advantage of being simple and are considered to be essential for quick calculations by chemical engineers, but they lack of precision and they are valid only at equilibrium. PBE-based models estimate the full DSD as a function of time and the programs run quite quickly, but they require a more detailed development.

\section{Modeling approaches}

In a turbulent flow regime, the Kolmogorov length scale of the smallest eddies is $\eta=\left(\frac{v^{3}}{\varepsilon}\right)^{1 / 4}$, where $v$ is the kinematic viscosity and $\varepsilon$ the turbulent energy dissipation rate [6]. At high Reynolds numbers, the universal equilibrium range is divided into two subranges: (1) The inertial subrange, $60 \eta \ll \lambda \ll \mathcal{L} / 6$ (where $\mathcal{L}$ is the scale of the largest vortices), in which the mean velocity fluctuation of an eddy of size $\lambda$ is $\overline{u_{\lambda}^{2}} \propto \varepsilon^{\frac{2}{3}} \lambda^{\frac{2}{3}} ;(2)$ and the dissipation or viscous subrange, $\eta \ll \lambda \ll 60 \eta$, with $\overline{u_{\lambda}^{2}} \propto \frac{\varepsilon \lambda^{2}}{v}$ (so dependent on the continuous phase viscosity) $[7,8]$.

The droplets formed in this work have mean diameters in the range of 51 to $132 \mu \mathrm{m}$, so they are mostly within the inertial subrange $(\eta=6.3-8.7 \mu \mathrm{m})$. Therefore, mean size correlations for this subrange will be investigated. There exist correlations for the dissipative subrange, but they will not be investigated here as they concern a small fraction of droplets [9]. Concerning population balance modeling, most kernels assume the inertial subrange.

\subsection{Flow characteristics in a pipe containing mixers}

The turbulent energy dissipation per unit mass of fluid can be estimated from the pressure drop $(\Delta \mathrm{P})$ in a pipe as follows:

$$
\varepsilon=\frac{\Delta P u_{i}}{\rho L}
$$

Where $\rho$ is the density, $L$ the tube length, and $u_{\mathrm{i}}$ is the interstitial velocity given by:

$$
u_{\mathrm{i}}=\frac{u_{\mathrm{s}}}{\varphi}=\frac{4 Q}{\pi D^{2}} \frac{1}{\varphi}
$$


Where $u_{\mathrm{s}}$ is the superficial velocity, $D$ the tube diameter, and $Q$ is the volumetric flow rate. The hydraulic tube diameter is related to the porosity of the pipes containing static mixers $(\varphi)$ and the mixer specific surface area $\left(a_{\mathrm{g}}\right)$ by $D_{\mathrm{h}}=4 \varphi / a_{\mathrm{g}}[10]$.

The apparent viscosity and density of the emulsion are related to the continuous (index c) and dispersed (index d) phase properties as follows $[9,11]$ :

$$
\begin{gathered}
\mu=\mu_{\mathrm{c}}\left[1+2.5 \phi\left(\frac{\mu_{\mathrm{d}}+2 / 5 \mu_{\mathrm{c}}}{\mu_{\mathrm{c}}+\mu_{\mathrm{d}}}\right)\right] \\
\rho=\phi \rho_{\mathrm{d}}+(1-\phi) \rho_{\mathrm{c}}
\end{gathered}
$$

Where $\phi$ is the dispersed phase volume fraction.

\subsection{Mean droplet size correlations}

The main correlations proposed to estimate the droplet mean size in the inertial subrange are given in Tab.

1. The velocity of the droplet is usually assumed equal to that of an eddy of the same size $\overline{u_{d}^{2}} \approx \overline{u_{\lambda}^{2}}$. For simplicity, the correlations in Tab. 1 were written using the constant $C_{1}$, but it does not have the same value in all correlations.

The original correlation was proposed by Kolmogorov (1949) [6] and Hinze (1955) [11], in which $d$ is proportional to $\varepsilon^{-\frac{2}{5}}$, or equivalently to $W e^{-\frac{3}{5}}$ (with the Weber number in a stirred vessel is We $=\frac{\rho \overline{u_{d}^{2}} d}{\sigma}$ and in a mixer $\mathrm{We}=\frac{\rho \overline{u_{l}^{2}} D_{\mathrm{h}}}{\sigma}, \sigma$ is the surface tension). An adaptation of this correlation to pipes containing mixers was proposed by Middleman (1974), introducing the dimensionless Newton $\left(\mathrm{Ne}_{\mathrm{h}}=2 f_{\mathrm{F}}=\frac{\Delta P}{\rho u_{\mathrm{i}}^{2}} \frac{D_{\mathrm{h}}}{L}\right)$ and Reynolds numbers $\left(\operatorname{Re}_{\mathrm{h}}=\frac{\rho u_{\mathrm{i}} D_{\mathrm{h}}}{\mu}\right)[12]$.

Effect of the dispersed phase fraction. Calderbank (1958) [13] introduced the damping effect of the dispersed phase volume fraction on energy dissipation, $d^{\phi} \propto d^{0}\left(1+C_{1} \phi\right)$, with $C_{1}=3.75$. Based on series expansion, Doulah (1975) [14] estimated $C_{1}=3$ for the inertial subrange, but other values were fitted empirically in the literature.

Effect of the dispersed phase viscosity and density. Chen and Libby (1978) [15] proposed an empirical correlation based on the viscosity ratio between the dispersed and continuous phases for static mixers. Davies (1985) [16] conducted a theoretical investigation and proposed that besides the cohesive energy due to interfacial tension, internal viscous forces may resist droplet breakage. This concept was adapted to mixers by Berkman and Calabrese (1988) [17]. Streiff et al. (1997) [18] proposed to explicitly relate the density ratio to the droplet size at equilibrium. 
Effect of residence time. The previously discussed correlations predict the droplet size at equilibrium. In the case of static mixers, this means that the number of mixers is high enough to ensure equilibrium between the breakage and coalescence phenomena and independence off the inlet droplet size. In order to make the correlation more general, it was empirically modified by introducing the number of mixers (see for instance Maa \& Hsu (1996) [19]).

Other correlations were proposed, mainly by fitting different powers of the different terms (see [20], [21] and references therein).

The correlation used in the present work to compare with the PBE is the following:

$$
d_{43}=C_{1} \varepsilon^{-\frac{2}{5}}\left(\frac{\sigma}{\rho_{\mathrm{c}}}\right)^{\frac{3}{5}}\left(\frac{\mu_{\mathrm{d}}}{\mu_{\mathrm{c}}}\right)^{C_{2}} n_{\mathrm{e}}^{-\mathrm{C}_{3}}
$$

This correlation accounts for the ratio of fluid inertia to surface forces as suggested by Kolmogorov and Hinze and for the viscosity ratio and the number of mixers. As $\varepsilon$ is calculated using equation 1 , based on the measured pressure drop, it already accounts for the damping effect, and there is no need for the $\phi$ term.

\subsection{Population balance equation based models}

PBE-based models are increasingly adopted since the last two decades for the representation of systems in which the properties are distributed and time-dependent. In the case of continuous emulsification using static mixers, few studies are reported in the literature $[28,29]$, with a noticeable lack in experimental data for the validation of the modeling approaches. These studies were recently reviewed by Lebaz and SheibatOthman (2019) [30].

\section{The population balance equation}

Due to the low dispersed phase fraction employed in this work, the presence of surfactant and the physicochemical properties of the oil, Ostwald ripening and coalescence are avoided, thus only breakage occurs [31]. The PBE governing the time evolution of the DSD when only breakage takes place in a spatially homogeneous system is given by:

$$
\frac{\partial n(v, t)}{\partial t}=\int_{v}^{\infty} \beta\left(v, v^{\prime}\right) g\left(v^{\prime}\right) n\left(v^{\prime}, t\right) d v^{\prime}-g(v) n(v, t)
$$

Where $n(v, t)$ is the number based DSD density, $v$ the droplet volume, $g(v)$ the breakage rate kernel for a droplet of volume $v$ and $\beta\left(v, v^{\prime}\right)$ is the daughter size distribution function.

\section{Breakage rate kernel modeling}

The breakage rate kernel in turbulent liquid-liquid dispersions has been widely studied in the literature. In this work, only two breakage rate kernels will be compared with the mean droplet size correlation, the kernels of Coulaloglou and Tavlarides (1977) [32] and Alopaeus et al. (2002) [5]. Indeed, the aim is not to 
investigate all the available kernels but to present the advantages and limitations of PBE and mean-size correlations.

One of the most widely used breakage rate kernels was proposed by Coulaloglou and Tavlarides (1977) [32] (referred to as CT model). In this phenomenological model, it is assumed that the droplets are in a locally isotropic turbulent flow field and the droplet size is within the inertial subrange. Their kernel is composed of two terms, a breakage frequency multiplied by a breakage probability. In the breakage probability term, they neglected the internal viscous forces and stated that an oscillating deformed drop will break if the turbulent kinetic energy transmitted to the droplet by turbulent eddies exceeds the surface energy [32], which gives:

$$
g(v)=C_{1} \frac{\varepsilon^{1 / 3}}{v^{2 / 9}} \exp \left(-\frac{C_{2} \sigma}{\rho_{d} \varepsilon^{2 / 3} v^{5 / 9}}\right)
$$

Where $C_{1}$ and $C_{2}$ are two adjustable constants.

In this study, the original model proposed by Coulaloglou and Tavlarides is modified in order to take into account the contribution of the viscous forces enhancing the cohesion of the droplets. For this, the breakage criterion is modified by stating that the cohesion of the droplets is due to its surface tension plus the internal viscous energies which should be overcome by the inertia to ensure breakup. This consideration leads to the breakage frequency given below:

$$
g(v)=C_{1} \frac{\varepsilon^{1 / 3}}{v^{2 / 9}} \exp \left(-\frac{C_{2} \sigma}{\rho_{c} \varepsilon^{2 / 3} v^{5 / 9}}-\frac{C_{3} \mu_{d}}{\sqrt{\rho_{c} \rho_{d}} \varepsilon^{1 / 3} v^{4 / 9}}\right)
$$

This kernel is similar to that proposed by Vankova et al. (2007) [33].

Besides the modified Coulaloglou breakage frequency model, the model proposed by Alopaeus et al. (2002) [5] will be used for comparison. This kernel takes into account both the surface and internal viscous energies as follows:

$$
g(v)=C_{1} \varepsilon^{1 / 3} \operatorname{erf} c\left(\sqrt{C_{2} \frac{\sigma}{\rho_{c} \varepsilon^{2 / 3} v^{5 / 9}}+C_{3} \frac{\mu_{d}}{\sqrt{\rho_{c} \rho_{d}} \varepsilon^{1 / 3} v^{4 / 9}}}\right)
$$

As in the correlations, the damping effect of the energy dissipation rate was also incorporated in these kernels [32]. Moreover, Doulah [14] and Alopaeus et al. (1999) [34] proposed to account for the viscosity and densities of both phases. As explained above, $\varepsilon$ is calculated in this work based on the measured pressure drop and it already accounts for the effects of $\phi$, and apparent viscosity and density.

\section{Daughter size distribution function}

The daughter size distribution function expresses the repartition of the volume over the daughter droplets formed after a breakage event. As in the case of breakage rate kernels, different models are proposed in the literature for the daughter size distribution function. In this study, the statistical model proposed by 
Hsia and Tavlarides (1983) [35] is adopted. This model assumes a binary breakage and the repartition of the daughter droplets is described by a beta function:

$$
\beta\left(v, v^{\prime}\right)=\frac{60}{v^{\prime}}\left(\frac{v}{v^{\prime}}\right)^{2}\left(1-\left(\frac{v}{v^{\prime}}\right)\right)^{2}
$$

\subsection{Numerical solution of the PBE}

The finite volume method developed initially by Filbet and Laurençot (2004) [36] to solve the Smoluchowski coagulation equation and extended later for aggregation and breakage by Kumar et al. (2009) [37] is adopted to solve the breakage PBE in this work. Details on its numerical implementation may be found in the two cited original articles.

\section{Materials and experimental methods}

\section{Materials}

Silicon oils (Bluestar Silicone, France) of different viscosities are dispersed in ultrapure water obtained using a Synergy unit system (Millipore, France) to form the oil-in-water pre-emulsions. Polysorbate 20 (Tween $20^{\circledR}$, supplied by Sigma-Aldrich, Germany) is used as surfactant.

\section{Experimental set-up and emulsification procedure}

The experimental set-up used in this study is shown in Fig. 1. First, a coarse oil-in-water emulsion is prepared by mixing silicon oil with pure water in which the surfactant is dissolved. This operation takes place in a $1 \mathrm{~L}$ mechanically agitated tank at a rotation speed of $500 \mathrm{rpm}$ during two hours for all experiments. Once the pre-emulsion is prepared, it is pumped through the static mixers. The mixers cause a pressure drop that is measured by a pressure gauge. Two samples of each experiment are withdrawn before and after the mixers and analyzed using a laser diffraction (Matersizer 3000, Malvern Instruments, France), thus eliminating the effects of the pump or other parts on the DSD.

Fig. 1

Stainless steel SMX+ static mixer elements (supplied by Sulzer) are used (Fig. 1 right). Each element is composed of six bars in each direction inclined by $45^{\circ}$ to the tube axis. The technical specifications of this static mixer type are given in Tab. 2. The SMX+ elements are inserted into a transparent polyvinyl chloride cylindrical tube of $5 \mathrm{~mm}$ of diameter which ensures good adhesion and avoids radial rotations. Different parameters are investigated experimentally and summarized in Tab. 3.

Tab. 2

Tab. 3 


\section{Results and discussion}

The three different models used for the prediction of the DSD and the $d_{43}$ involve parameters $\left(C_{1}, C_{2}\right.$ and $C_{3}$ ) that need to be identified. Thus, as a first step, a numerical optimization is performed for parameters identification.

\section{Parameters identification}

In the case of the population balance models, two different experiments ( 5 and 8 in Tab. 3 ) are combined for parameters identification. This is achieved by minimizing the least squares between the experimental DSD and the model predictions at the outlet of the mixers. For the identification of the mean-size correlation parameters, all the experimental database in Tab. 3 is used. In this case, the minimization criterion is the least squares between the experimental $d_{43}$ at the outlet of the mixers and that predicted by the correlation. The numerical optimization procedure is implemented in MATLAB using the Global Optimization Toolbox. The results are shown in Tab. 4.

Tab. 4

In the kernels, a higher $C_{1}$ value indicates a higher breakage frequency while higher $C_{2}$ or $C_{3}$ indicate a lower breakage probability. The parameter $C_{2}$ is related to the ratio of the surface tension to the inertia while the parameter $C_{3}$ is related to the dispersed phase viscosity. In both kernels, the value of $C_{2}$ mixers was identified in static to be almost 100 times higher than in stirred tanks, indicating a reduced breakage probability, or a higher ratio of the surface force to the inertial force. Similarly, Azizi et al. identified high values of $C_{2}$ in static mixers, using the Coulaloglou and Tavlarides kernel [29]. Also, the extent of the ratio $C_{3} / C_{2}$ indicates the contribution of the viscosity group. It appears that this ratio is much lower in static mixers than in stirred tanks, indicating that the dispersed phase viscosity effect is negligible, i.e. increasing the viscosity does not decrease the breakage probability. This might be due to the higher energy dissipation, and its uniformity, in these mixers. Finally, the estimated value of $C_{1}$ in static mixers is only slightly higher than in stirred tanks for both kernels, while Azizi et al. identified higher values of $C_{1}$ in static mixers, thus indicating a higher breakage frequency in the mixers. The fact that different values of the kernels' parameters are obtained in the literature in stirred tanks is partly due to the fact that the stirred tank leads to non-uniform energy dissipation. As in static mixers the energy dissipation is more uniform, one may believe that the obtained parameters are more fundamental. However, the energy is much higher which might suppress other phenomena that exist in the stirred tank.

\section{Effect of the number of static mixer elements}

The number of SMX+ mixing elements was varied from one to ten. The comparison between the experimental data and the prediction of the different models expressed in term of $d_{43}$ is shown in Fig. 2. 
Fig. 2

Experimentally, increasing the number of mixing elements increases the residence time inside the mixers. Therefore, the droplets are exposed to the turbulence for a longer time which increases the breakage events. This explains the decrease of the droplet mean diameter, from $87 \mu \mathrm{m}$ to $75 \mu \mathrm{m}$, when the number of SMX+ elements increases from 1 to 8 . Using more than 8 elements does not affect the $d_{43}$ since equilibrium is reached. Note that the number of mixers ensuring the equilibrium would change if the dispersed phase viscosity or volume fraction are changed. In this figure, they were quite low $\left(\mu_{d}=50 \mathrm{mPa} . \mathrm{s}\right.$ and $\phi=1 \%)$.

The mean diameter predicted by the correlation is acceptable except when only one SMX+ mixer is used. In this case, the correlation overestimates the mean diameter while the PBE-based models are more accurate. Only when using $10 \mathrm{SMX}+$ elements, the predictions of the PBE-based models appear less accurate than the correlation. The PBE-based model predicts bigger sizes with 10 mixers than with 8 mixers as the inlet DSD was bigger in this case. It can be concluded that the correlation is in general acceptable to estimate the transient evolution of the mean diameter, however it remains independent of the inlet droplet size.

Fig. 3

The use of the PBE allows to track the full DSD with time (Fig. 3). Both breakage rate kernels give equivalent predictions of the DSD in the different cases. A good agreement between the predictions and the experimental data is observed. Indeed, both models account for the same phenomena in a comparative way, and their parameters were identified individually.

\section{Effect of the dispersed phase viscosity}

The effect of the dispersed phase viscosity on the DSD and its mean size is reported in Fig. 4.

Fig. 4

As expected, when the dispersed phase is becoming more viscous, it requires more energy to break. The mean diameter shows a strong variation from $d_{43}=51 \mu \mathrm{m}$ for the low viscosity oil to $d_{43}=132 \mu \mathrm{m}$ for the highly viscous oil. The PBE-based model predictions using the two different breakage rate kernels are very close to the experimental measurements while the correlation deviates in some cases (Fig. 4 for the mean diameter and Fig. 5 for the full DSD). The error of the PBE-based model is around $10 \%$ in the worst case $\left(d_{43}\right.$ predicted using the modified Coulaloglou breakage rate kernel for the oil of $\mu_{d}=50 \mathrm{mPa} . \mathrm{s}$ ) and the error of the correlation when using the lowest viscous oil is around $50 \%$. This error is partially due to the fact that the distribution may be wide, especially when increasing the viscosity (as shown in Fig. 5) and cannot be described by a single mean diameter. For the oil with $\mu_{d}=50 \mathrm{mPa}$.s, it can be seen that the 
correlation is predicting a smaller diameter that the oil with $\mu_{d}=20 \mathrm{mPa}$.s. This is due to the fact that the correlation includes the energy dissipation that is obtained from the experimental pressure drop, which may be noisy due to the very short residence time. For the oil of $\mu_{\mathrm{d}}=200 \mathrm{mPa} . \mathrm{s}$, the DSD generated in the premixing step was of small size. As the PBE-based model accounts for the inlet (or initial) DSD, it could predict the outlet while the correlation could not as it is independent of the inlet. A change in the initial DSD might occur for a number of reasons, like impurity or evolutions in the set-up or pumps, and it is important to have a model robust to such evolutions.

Fig. 5

It can be seen in Fig. 5 that the inlet DSD changes when changing the oil viscosity, even though the preemulsions are prepared under the same conditions for the different oils. The efficiency of the mixers over the stirred tank is obvious as a big reduction in the droplet size is obtained in few seconds.

\section{Effect of the dispersed phase volume fraction}

The dispersed phase volume fraction was varied from $1 \%$ to $5 \%$ for the same silicon oil of $\mu_{\mathrm{d}}=50 \mathrm{mPa} . \mathrm{s}$ at the same flow rate using 10 SMX+ elements. The evolution of the droplet mean diameter is shown in Fig. 6. Experimentally, the droplets mean diameter $d_{43}$ increases slightly from $76 \mu \mathrm{m}$ to $84 \mu \mathrm{m}$ when the dispersed phase volume fraction increases from $1 \%$ to $5 \%$. Indeed, when increasing the volume fraction a higher energy is required for breakup due to the energy damping effect. This effect is clearly visible at the outlet of the stirred tank, but also at the outlet of the mixers.

Fig. 6

The predictions of the transient correlation are acceptable with a slight underestimation of the mean diameter (around 5\% for the worst case). The main error in the correlation is due to the fact that it is independent of the inlet which varies in this case. Note also that the low fraction of the dispersed phase only slightly impacts the pressure drop, therefore the impact of increasing $\phi$ on $\varepsilon$ may not be measured precisely. It would probably help to explicitly account for energy damping into the correlation. This is not the case when using the PBE-based model as showed in Fig. 7. This approach captures very well the DSD and the $d_{43}$ especially with the Alopaeus breakage rate kernel.

Fig. 7

\section{Effect of the volume-average turbulent energy dissipation rate}

By varying the flow rate of the pre-emulsion, the volume-average energy dissipation rate was varied between $172 \mathrm{~m}^{2} \mathrm{~s}^{-3}$ and $626 \mathrm{~m}^{2} \mathrm{~s}^{-3}$. The experimental results and the predictions of the different models are given in Fig. 8 and Fig. 9.

Fig. 8 
Fig. 9

As expected, the increase of $\varepsilon$ has a direct effect on the droplet mean size which decreases from $d_{43}=81$ $\mu \mathrm{m}$ to $d_{43}=63 \mu \mathrm{m}$. The increase of $\varepsilon$ means that the collision frequency between the turbulent eddies and the oil droplets increases which increases the number of breakage events. Moreover, the breakage probability increases due to the higher inertia compared to surface or viscous forces. This effect is captured accurately by the correlation except for the lowest $\varepsilon$, where the error is of $20 \%$, probably because it is far from equilibrium. The PBE-based models give excellent predictions of the mean diameter and the DSD at the outlet of the mixers for all the ranges of $\varepsilon$ using the two different breakage rate kernels.

To summarize, Fig. 10 shows the predicted mean diameters of the set of experiments using the correlation and the PBE-based models versus the experimental data. As discussed in the previous sections and for all the investigated parameters, the PBE based models accurately predict the droplet mean diameter while the correlation fails in some specific cases. Moreover, the use of the Alopaeus breakage rate kernel gives slightly more accurate estimations of the mean droplet size than the modified Coulaloglou model.

Fig. 10

\section{Conclusion}

Modeling continuous emulsification processes using static mixers is reported. Two different approaches are investigated and their performances compared in the case of turbulent breakage dominant systems: equilibrium correlations predicting the mean droplet size and PBE-based models tracking the full DSD. The proposed correlation accounts for the ratio of surface forces to fluid inertia, the viscosity ratio between the dispersed and continuous phases and the volume-average turbulent energy dissipation rate. To allow for transient state predictions, the number of mixing elements is incorporated, but the correlation still does not account for the initial droplet size. In the case of PBE-based models, two different breakage rate kernels are adopted: the modified Coulaloglou model and the Alopaeus et al. model. Both kernels take into account the contribution of surface and viscous forces in the cohesive energy against the disruptive energy of the turbulence. The effect of the operating conditions is also investigated experimentally. The advantages and drawbacks of the two approaches are summarized below:

- The mean diameter predicted by the correlation is acceptable except for some cases that bring the system far from equilibrium, such as for low energy dissipation, small number of mixers or when the initial DSD varies in an unpredictable way (bringing the system out of the model validity). Thus, the correlations represent a useful tool for a fast estimation of the mean size.

- The use of PBE-based models allows an accurate prediction of the entire DSD as well as the mean droplet size and the simulation time is of the order of few seconds. But this requires to implement the input DSD and the formalism is more complex. 
- The numerical prediction of the DSD is approximately equivalent for both of the investigated breakage rate kernels, as they both rely on fitting parameters and account for the same phenomena in a comparative way.

- The use of correlations requires a large amount of experimental data for a judicious identification of the parameters. This is not the case for PBE-based models where only two experiments were used for fitting.

- The identified kernel parameters indicate a higher breakage frequency but a lower breakage probability in the static mixers compared to stirred tanks.

\section{References}

[1] F. Theron, N. Le Sauze, Int. J. Multiph. Flow. 2011, 37 (5), 488-500. DOI: 10.1016/j.ijmultiphaseflow.2011.01.004.

[2] A. Ghanem, T. Lemenand, D. Della Valle, H. Peerhossaini, Chem. Eng. Res. Des. 2014, 92 (2), 205-228. DOI: 10.1016/j.cherd.2013.07.013.

[3] R. V. Calabrese, T. P. K. Chang, P. T. Dang, AlChE J. 1986, 32 (4), 657-666.

[4] A. Kolmogorov, in Dokl Akad Navk SSSR, Vol. 661949.

[5] V. Alopaeus, J. Koskinen, K. I. Keskinen, J. Majander, Chem. Eng. Sci. 2002, 57 (10), 1815-1825. DOI: 10.1016/S0009-2509(02)00067-2.

[6] A. N. Kolmogorov, in Dokl Akad Nauk SSSR, Vol. 301941.

[7] S. B. Pope, Turbulent Flows, Cambridge University Press, Cambridge 2000.

[8] M. Karimi, R. Andersson, Chem. Eng. Sci. 2018, 192, 850-863. DOI: 10.1016/j.ces.2018.08.016.

[9] G. I. Taylor, Proc. R. Soc. Lond. Ser. Contain. Pap. Math. Phys. Character. 1932, 138 (834), 41-48.

[10] M. Pahl, E. Muschelknautz, Chem. Ing. Tech. 1980, 52 (4), 285-291. DOI: 10.1002/cite.330520402.

[11] J. O. Hinze, AlChE J. 1955, 1 (3), 289-295. DOI: 10.1002/aic.690010303.

[12] S. Middleman, Ind. Eng. Chem. Process Des. Dev. 1974, 13 (1), 78-83. DOI: 10.1021/i260049a015.

[13] P. H. Calderbank, Trans Inst Chem Engrs. 1958, 36, 443-463.

[14] M. S. Doulah, Ind. Eng. Chem. Fundam. 1975, 14 (2), 137-138. DOI: 10.1021/i160054a015.

[15] S. J. Chen, D. R. Libby, in 71st Annu. AlChE Meet., Miami 1978.

[16] J. T. Davies, Chem. Eng. Sci. 1985, 40 (5), 839-842. DOI: 10.1016/0009-2509(85)85036-3.

[17] P. D. Berkman, R. V. Calabrese, AIChE J. 1988, 34 (4), 602-609.

[18] F. A. Streiff, P. Mathys, T. U. Fischer, Récents Prog. En Génie Procédés. 1997, 11 (51), 307-314.

[19] Y. F. Maa, C. Hsu, J. Microencapsul. 1996, 13 (4), 419-433. DOI: 10.3109/02652049609026028.

[20] M. P. Vasilev, R. S. Abiev, Chem. Eng. J. 2018, 349, 646-661.

[21] F. Theron, N. Le Sauze, A. Ricard, Ind. Eng. Chem. Res. 2010, 49 (2), 623-632. DOI: 10.1021/ie900090d.

[22] Y. Mlynek, W. Resnick, AIChE J. 1972, 18 (1), 122-127. DOI: 10.1002/aic.690180122.

[23] D. Brown, K. Pitt, in Br. Chem. Eng., Vol. 161971.

[24] M. Poux, J.-P. Canselier, Tech. Ing. 2004, (j2153).

[25] R. V. Calabrese, T. P. K. Chang, P. T. Dang, AlChE J. 1986, 32 (4), 657-666. DOI: 10.1002/aic.690320416.

[26] E. W. Barega, E. Zondervan, A. B. de Haan, Ind. Eng. Chem. Res. 2013, 52 (8), 2958-2968. DOI: 10.1021/ie301580m.

[27] E. Chabanon, N. Sheibat-Othman, O. Mdere, J. P. Valour, S. Urbaniak, F. Puel, Int. J. Multiph. Flow. 2017, 92, 61-69. DOI: 10.1016/j.ijmultiphaseflow.2017.03.001.

[28] Z. Jaworski, P. Pianko-Oprych, D. L. Marchisio, A. W. Nienow, Chem. Eng. Res. Des. 2007, 85 (5), 753759. DOI: $10.1205 /$ cherd06179.

[29] F. Azizi, A. M. Al Taweel, Chem. Eng. J. 2011, 166 (2), 715-725. 
[30] N. Lebaz, N. Sheibat-Othman, Chem. Eng. J. 2019, 361, 625-634. DOI: 10.1016/j.cej.2018.12.090.

[31] N. B. Raikar, S. R. Bhatia, M. F. Malone, M. A. Henson, Chem. Eng. Sci. 2009, 64 (10), 2433-2447. DOI: 10.1016/j.ces.2009.01.062.

[32] C. A. Coulaloglou, L. L. Tavlarides, Chem. Eng. Sci. 1977, 32 (11), 1289-1297. DOI: 10.1016/00092509(77)85023-9.

[33] N. Vankova, S. Tcholakova, N. D. Denkov, V. D. Vulchev, T. Danner, J. Colloid Interface Sci. 2007, 313 (2), 612-629.

[34] V. Alopaeus, J. Koskinen, K. I. Keskinen, Chem. Eng. Sci. 1999, 54 (24), 5887-5899.

[35] M. A. Hsia, L. L. Tavlarides, Chem. Eng. J. 1983, 26 (3), 189-199. DOI: 10.1016/0300-9467(83)80014-8.

[36] F. Filbet, P. Laurençot, SIAM J. Sci. Comput. 2004, 25 (6), 2004-2028.

[37] J. Kumar, G. Warnecke, M. Peglow, S. Heinrich, Powder Technol. 2009, 189 (2), 218-229. 


\section{Tables}

Table 1: Mean diameter correlations for single emulsions, under turbulent conditions, in the inertial subrange

\begin{tabular}{|c|c|c|c|}
\hline Contribution & Mean (or maximum) diameter correlation & Geometry & Ref. \\
\hline \multirow[t]{2}{*}{$\begin{array}{l}\text { Accounts for the fluid inertia } \\
\text { to the surface tension }\end{array}$} & $\begin{array}{ll}\text { Function of } \varepsilon: & \text { Equivalently, function of } W e: \\
d \propto \varepsilon^{-\frac{2}{5}}\left(\frac{\sigma}{\rho_{\mathrm{c}}}\right)^{\frac{3}{5}} & d / D_{\mathrm{I}} \propto \mathrm{We}^{-\frac{3}{5}}\end{array}$ & $\begin{array}{l}\text { Stirred tank, } \\
\text { Pipe }\end{array}$ & {$[4,11]$} \\
\hline & \begin{tabular}{l|l}
$d / D_{h} \propto \mathrm{Ne}_{\mathrm{h}}^{-\frac{2}{5}} \mathrm{We}_{\mathrm{h}}^{-\frac{3}{5}}$ & Assuming $\mathrm{Ne}_{\mathrm{h}} \propto \mathrm{Re}_{\mathrm{h}}^{-\frac{1}{4}}:$ \\
$d / D_{\mathrm{h}} \propto \mathrm{Re}_{\mathrm{h}}^{\frac{1}{10}} \mathrm{We}_{\mathrm{h}}^{-\frac{3}{5}}$
\end{tabular} & Static mixers & {$[12]$} \\
\hline \multirow[t]{2}{*}{$\begin{array}{l}\text { To account for the dispersed } \\
\text { phase fraction, } \phi\end{array}$} & $\begin{array}{l}d / D_{\mathrm{I}} \propto\left(1+C_{1} \phi\right) \mathrm{We}^{-\frac{3}{5}} \\
C_{1}=3.75 \text { for Calderbank, other values are available } \\
{[14,22,23]}\end{array}$ & Stirred tank & [13] \\
\hline & $d / D_{\mathrm{h}} \propto\left(1+C_{1} \phi\right) \mathrm{We}^{-\frac{3}{5}}$ & Static mixers & {$[24]$} \\
\hline \multirow{4}{*}{$\begin{array}{l}\text { To account for the dispersed } \\
\text { phase viscosity, } \mu_{d}\end{array}$} & $d / D_{h} \propto \mathrm{We}^{-\frac{3}{4}}\left(\frac{\mu_{\mathrm{d}}}{\mu_{\mathrm{c}}}\right)^{0.18}$ & Static mixers & {$[15]$} \\
\hline & $d \propto \varepsilon^{-\frac{2}{5}}\left(\frac{\sigma+\mu_{\mathrm{d}} \overline{u_{d}} / 4}{\rho_{\mathrm{c}}}\right)^{\frac{3}{5}}$ & Stirred tank & {$[16]$} \\
\hline & $\frac{d^{\frac{5}{3}} \rho_{c} \varepsilon^{-\frac{2}{3}}}{\sigma} \propto\left(1+\mathrm{C}_{1}\left(\frac{\rho_{\mathrm{c}}}{\rho_{\mathrm{d}}}\right)^{\frac{1}{2}} \frac{\mu_{d} \varepsilon^{-\frac{1}{3}} d^{\frac{1}{3}}}{\sigma}\right)$ & Stirred tank & {$[25]$} \\
\hline & $d / D_{\mathrm{h}} \propto\left(1+\mathrm{C}_{1}\left(\frac{\mu_{\mathrm{d}}}{\mu_{\mathrm{c}}}\right)\left(\frac{d}{D_{\mathrm{h}}}\right)^{\frac{1}{3}} \frac{\mathrm{We}_{\mathrm{h}} \mathrm{Ne}_{\mathrm{h}}^{\frac{1}{3}}}{\mathrm{Re}_{\mathrm{h}}}\right)^{\overline{5}} \mathrm{We}_{\mathrm{h}}^{-\frac{3}{5}} \mathrm{Ne}_{\mathrm{h}}^{-\frac{2}{5}}$ & Static mixers & {$[17]$} \\
\hline $\begin{array}{l}\text { To account for the density } \\
\text { ratio }\end{array}$ & $d \propto \varepsilon^{-\frac{2}{5}}\left(\frac{\sigma}{\rho_{\mathrm{c}}}\right)^{\frac{3}{5}}\left(\frac{\rho_{\mathrm{c}}}{\rho_{\mathrm{d}}}\right)^{\frac{1}{10}}$ & Static mixers & {$[18]$} \\
\hline $\begin{array}{l}\text { Explicit function } \\
\text { superficial velocity }\end{array}$ & $\begin{array}{l}d / D \propto\left(1+C_{1} \phi\right)\left(\frac{\rho u_{s}^{2} D}{\sigma}\right)^{\alpha(\phi)}\left(\frac{\rho u_{s} D}{\mu_{c}}\right)^{\beta(\phi)}\left(\frac{\mu_{\mathrm{d}}}{\mu_{\mathrm{c}}}\right)^{\gamma} \\
\text { Where } \alpha(\phi), \beta(\phi) \text { and } \gamma \text { are tuning functions. }\end{array}$ & Static mixers & {$[26]$} \\
\hline \multirow{2}{*}{$\begin{array}{l}\text { To account for the number } \\
\text { of mixers }\left(n_{e}\right) \text { (transient } \\
\text { state) }\end{array}$} & $d / D \propto \mathrm{C}_{1} \mathrm{We}^{-\frac{3}{5}} \mathrm{Re}^{\frac{1}{10}} n_{\mathrm{e}^{-\frac{1}{5}}}$ & Static mixers & [19] \\
\hline & $\begin{array}{l}d_{32} \propto \varepsilon^{-\frac{2}{5}}\left(\frac{\sigma}{\rho_{\mathrm{c}}}\right)^{\frac{3}{5}} n_{\mathrm{e}}^{-C_{1}} \\
\left.\mathrm{We}_{\mathrm{h}}^{-\frac{3}{5}} \mathrm{Ne}_{\mathrm{h}}^{-\frac{2}{5}} n_{\mathrm{e}}^{-C_{1}}\right)\end{array}$ & Static mixers & {$[27]$} \\
\hline
\end{tabular}


Table 2: Technical characteristics of the Sulzer SMX+ static mixer

\begin{tabular}{|c|c|}
\hline Static mixer element & SMX+ \\
\hline Length: $L$ & $5 \mathrm{~mm}$ \\
\hline Diameter: $D$ & $5 \mathrm{~mm}$ \\
\hline Specific surface area: $a_{\mathrm{g}}$ & $1527 \mathrm{~m}^{2} \cdot \mathrm{m}^{-3}$ \\
\hline Global porosity: $\phi$ & $75 \%$ \\
\hline Hydraulic diameter: $D_{\mathrm{h}}$ & $1.42 \times 10^{-3} \mathrm{~m}$ \\
\hline
\end{tabular}

Table 3: List of experiments carried out by varying the number of SMX+ element, the viscosity of the dispersed phase $\left(\mu_{\mathrm{d}}\right)$, the volume-average turbulent kinetic energy $(\varepsilon)$ and the dispersed phase fraction $(\phi)$.

\begin{tabular}{|c|c|c|c|c|}
\hline Experiment & $\begin{array}{c}\text { Number of SMX+ } \\
\text { elements }\end{array}$ & $\mu_{\mathrm{d}}$ (mPa.s) & $\varepsilon\left(\mathrm{m}^{2} \cdot \mathrm{s}^{-3}\right)$ & $\phi(\%)$ \\
\hline 1 & 1 & 50 & 314 & 1 \\
\hline 2 & 4 & 50 & 314 & 1 \\
\hline 3 & 8 & 50 & 314 & 1 \\
\hline 4 & 10 & 50 & 314 & 1 \\
\hline 5 & 10 & 20 & 314 & 1 \\
\hline 6 & 10 & 100 & 314 & 1 \\
\hline 7 & 10 & 200 & 314 & 1 \\
\hline 8 & 10 & 350 & 314 & 1 \\
\hline 9 & 10 & 50 & 314 & 2 \\
\hline 10 & 10 & 50 & 314 & 3 \\
\hline 11 & 10 & 50 & 314 & 4 \\
\hline 12 & 10 & 50 & 314 & 5 \\
\hline 13 & 10 & 50 & 172 & 1 \\
\hline 14 & 10 & 50 & 430 & 1 \\
\hline 15 & 10 & 50 & 626 & 1 \\
\hline
\end{tabular}


Table 4: Breakage frequencies and correlation constants obtained by optimization

\begin{tabular}{|c|c|c|c|c|c|c|c|c|}
\hline & \multicolumn{3}{|c|}{$\mathrm{C}_{1}$} & \multicolumn{3}{|c|}{$C_{2}$} & \multicolumn{2}{|c|}{$C_{3}$} \\
\hline & $\begin{array}{l}\text { This } \\
\text { work } \\
\text { (static } \\
\text { mixers) }\end{array}$ & $\begin{array}{l}\text { Original } \\
\text { (stirred } \\
\text { tank) }\end{array}$ & $\begin{array}{c}\text { Aziz. et al. } \\
\text { [29] } \\
\text { (static } \\
\text { mixers) }\end{array}$ & $\begin{array}{l}\text { This } \\
\text { work } \\
\text { (static } \\
\text { mixers) }\end{array}$ & $\begin{array}{c}\text { Original } \\
\text { (stirred } \\
\text { tank) }\end{array}$ & $\begin{array}{l}\text { Aziz. et } \\
\text { al. [29] } \\
\text { (static } \\
\text { mixers) }\end{array}$ & $\begin{array}{c}\text { This work } \\
\text { (static } \\
\text { mixers) }\end{array}$ & $\begin{array}{c}\text { Original } \\
\text { (stirred } \\
\text { tank) }\end{array}$ \\
\hline $\begin{array}{l}\text { Coulaloglou \& } \\
\text { Tavlarides model }\end{array}$ & 0.02 & $4.87 \times 10^{-3}$ & 0.86 & 2.02 & 0.0552 & 4.1 & $\begin{array}{c}2.2 \times 10^{-8} \\
\sim 0\end{array}$ & - \\
\hline $\begin{array}{l}\text { Alopaeus et al. } \\
\text { model }\end{array}$ & 4.06 & 0.986 & - & 0.59 & $0.892 \times 10^{-3}$ & - & $\begin{array}{c}2.3 \times 10^{-14} \\
\sim 0\end{array}$ & 0.2 \\
\hline $\begin{array}{l}\text { Mean size } \\
\text { correlation }\end{array}$ & 0.20 & - & - & 0.27 & - & - & 0.03 & - \\
\hline
\end{tabular}


Figures

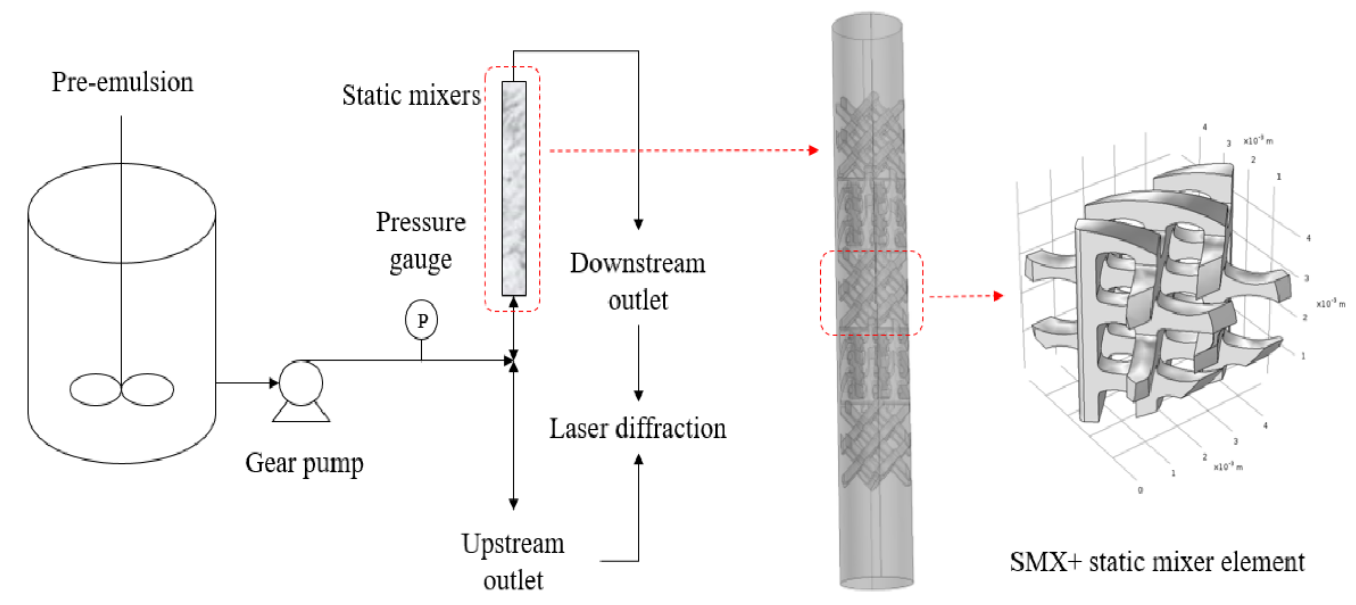

Fig. 1: Schematic representation of the experimental set-up (left) and the 3D geometric structure of the $\mathrm{SMX}+$ static mixer (right) 


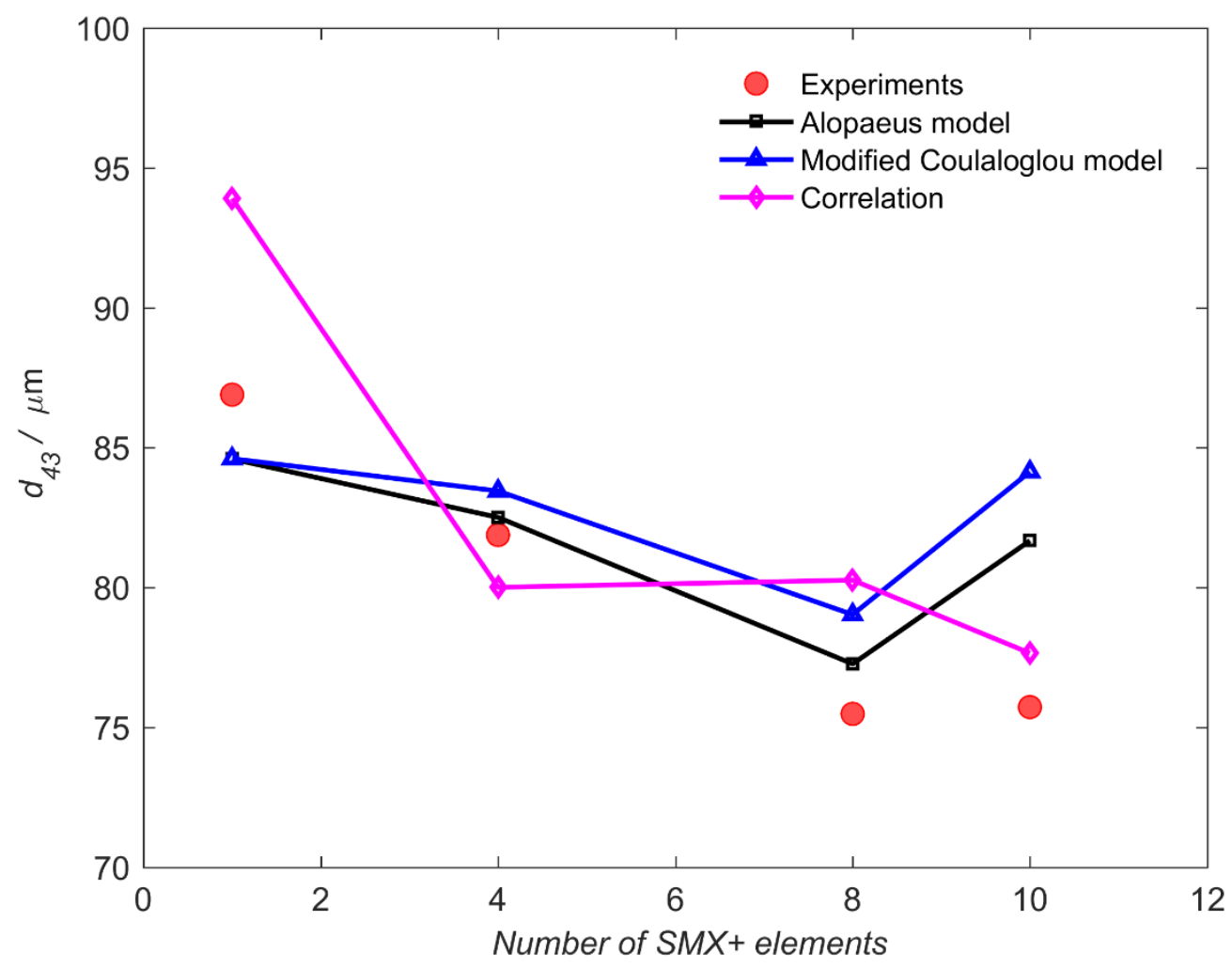

Fig. 2: Effect of the number of $S M X+$ on the volume-based mean diameter $\mathrm{d}_{43}$ : experimental data (experiments 1, 2, 3 and 4 in Tab. 3) versus models predictions 
(a)

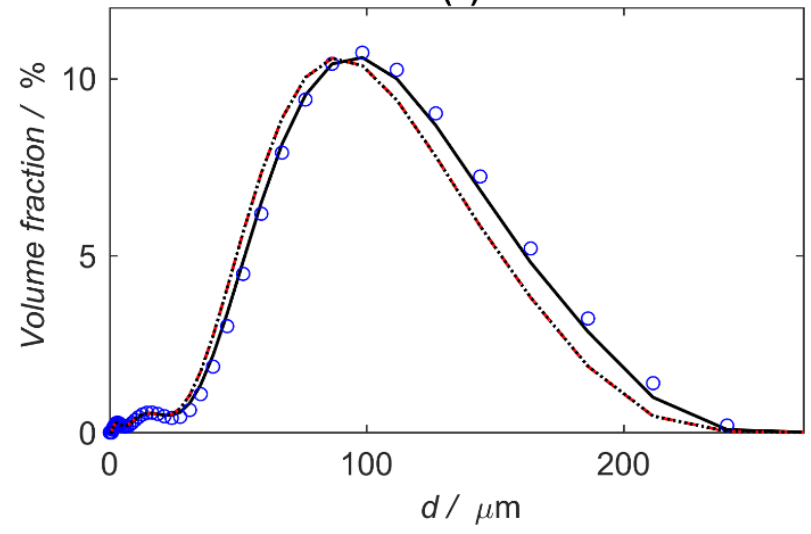

(b)

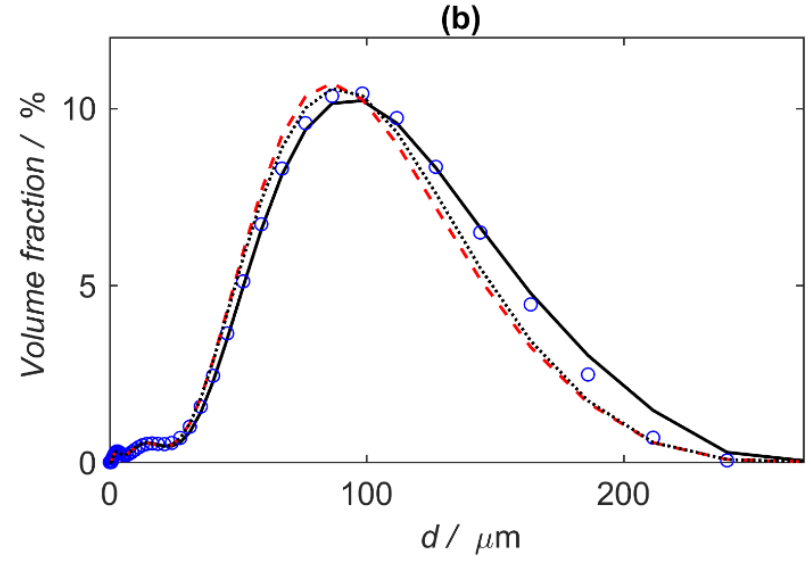

(c)

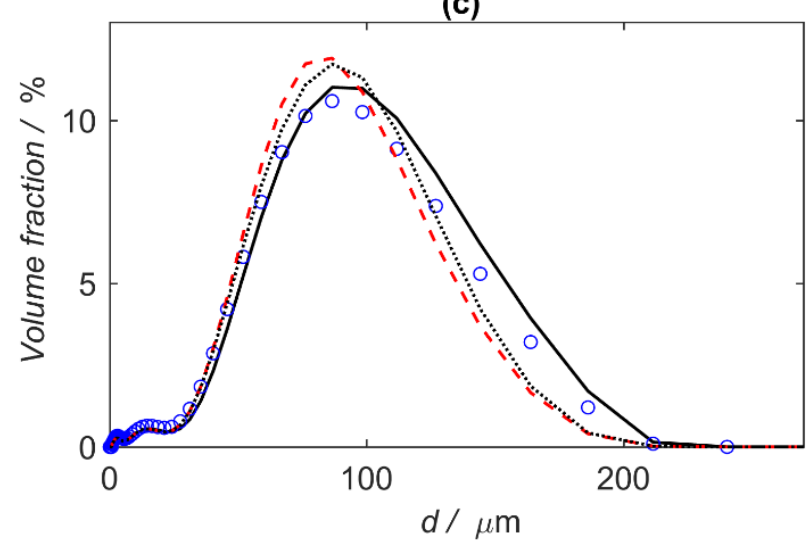

(d)

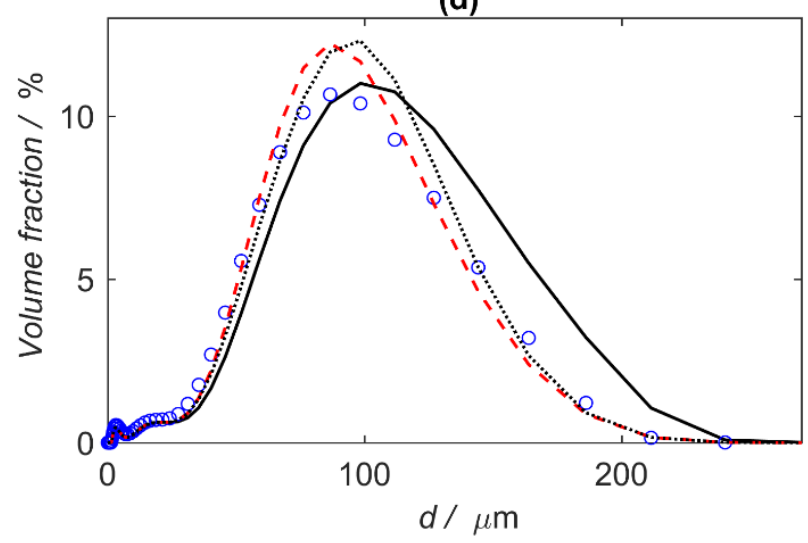

Fig. 3: Effect of the number of SMX+ on the DSD: experimental data (inlet: solid line, outlet: circles) vs model predictions (dashed line: Alopaeus model, dotted line: modified Coulaloglou model): (a) 2 SMX+ elements, (b) $4 \mathrm{SMX}+$ elements, (c) $8 \mathrm{SMX}+$ elements and (d) $10 \mathrm{SMX}+$ elements 


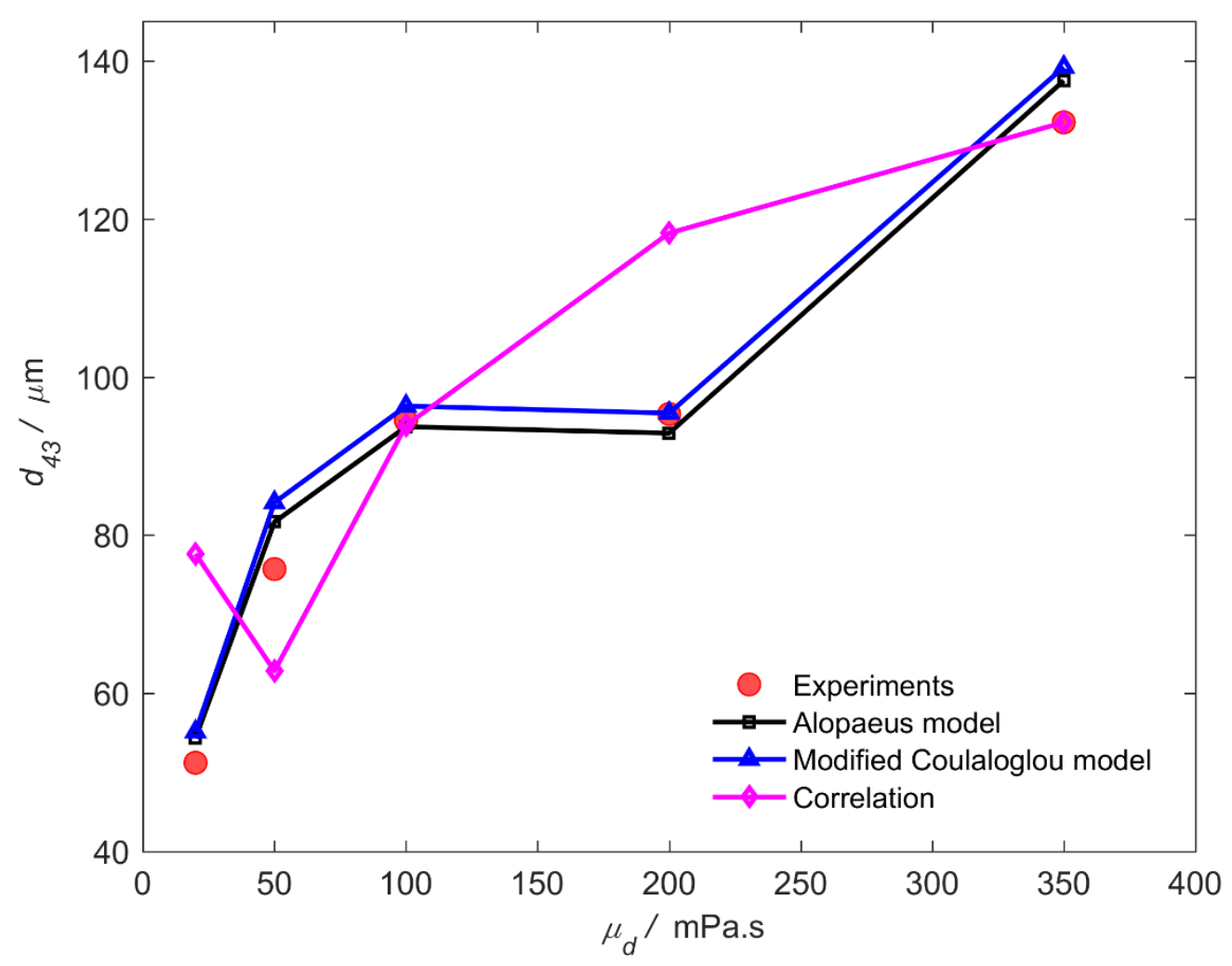

Fig. 4: Effect of the dispersed phase viscosity on the volume-based mean diameter $\mathrm{d}_{43}$ : experimental data (experiments 4, 5, 6, 7 and 8 in Tab. 3) vs model predictions 
(a)

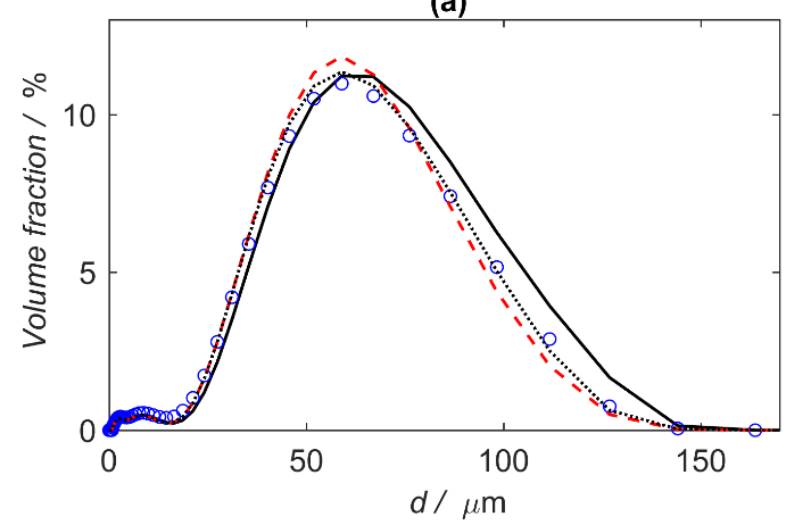

(b)

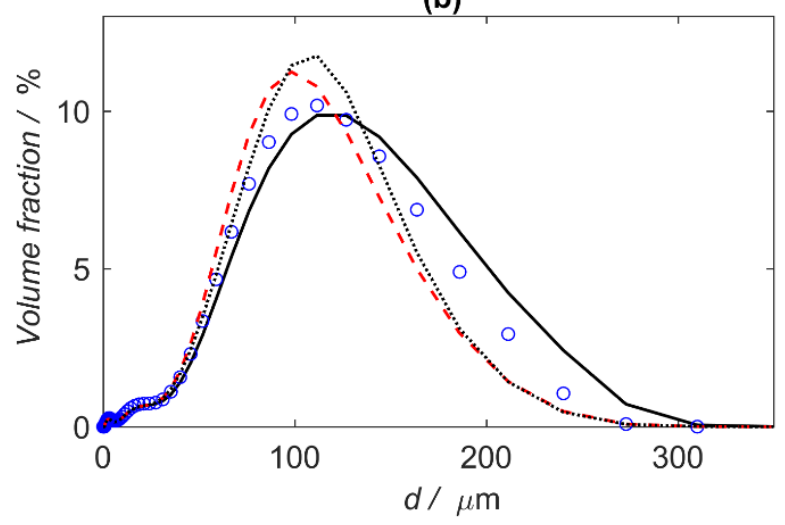

(c)

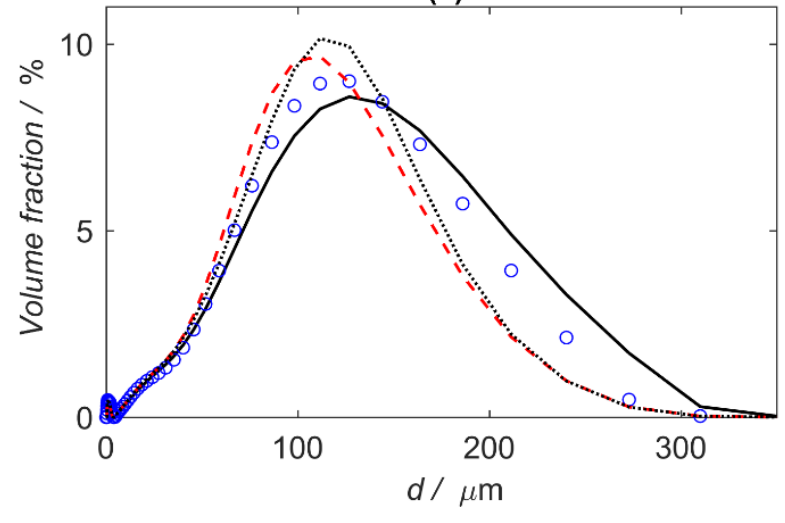

(d)

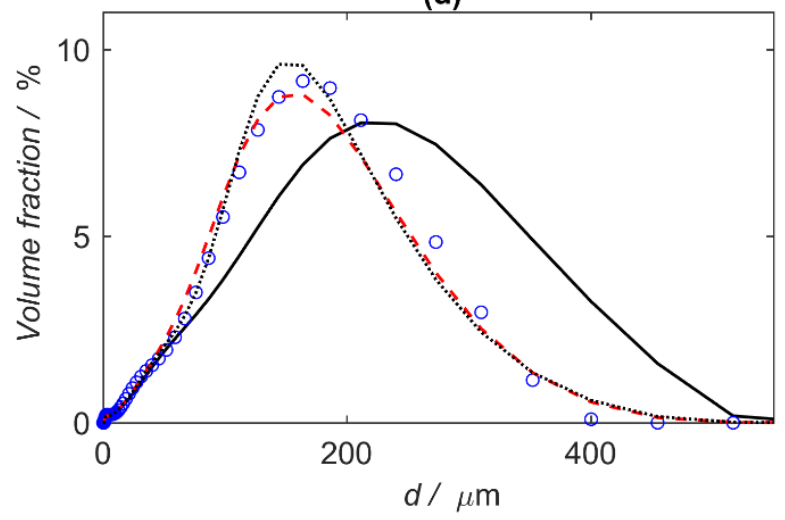

Fig. 5: Effect of the dispersed phase viscosity on the DSD: (inlet: solid line, outlet: circles) vs model predictions (dashed line: Alopaeus model, dotted line: modified Coulaloglou model): (a) 20 mPa.s, (b) 100 mPa.s, (c) $200 \mathrm{mPa} . \mathrm{s}$ and (d) $350 \mathrm{mPa} . \mathrm{s}$ 


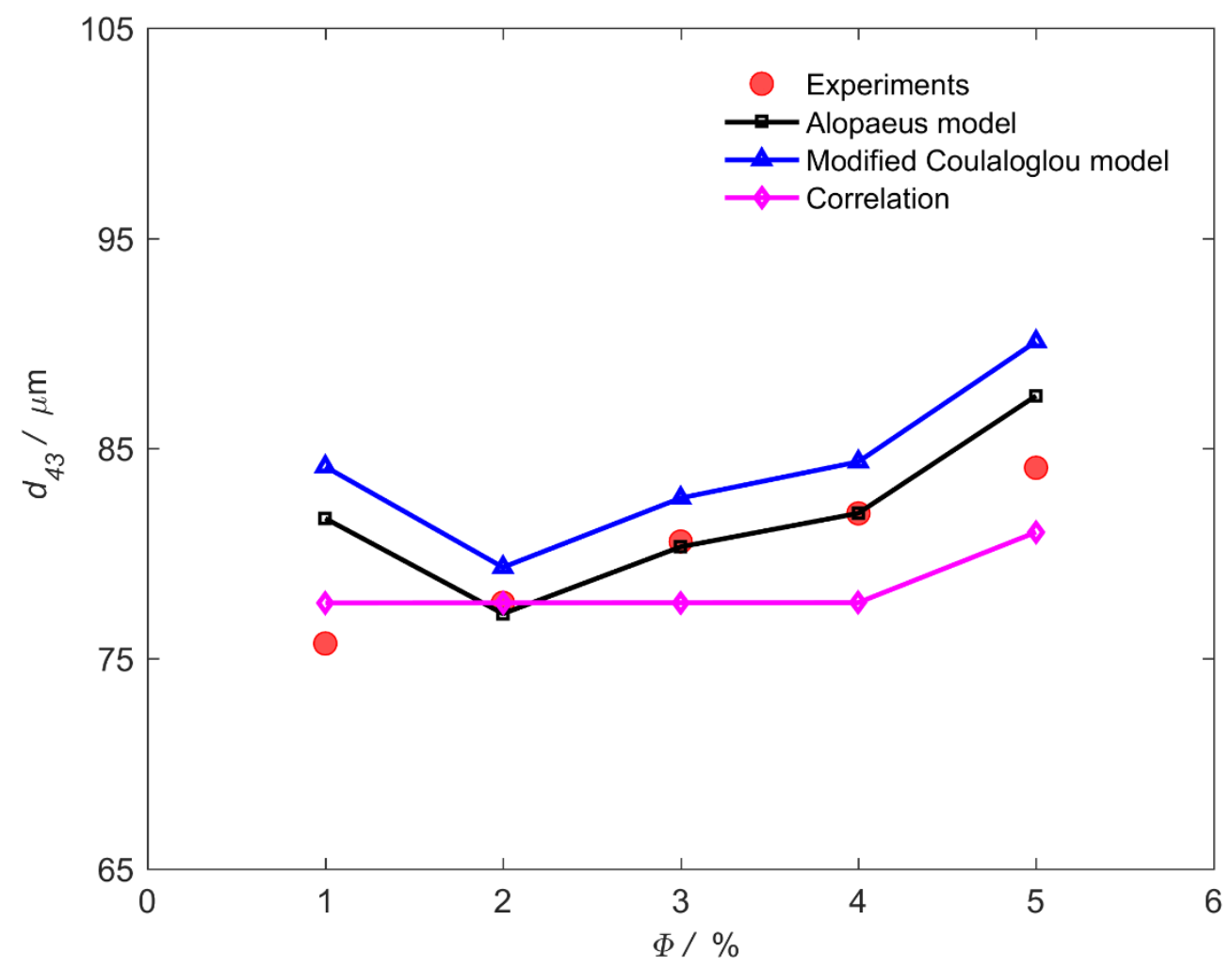

Fig. 6: Effect of the dispersed phase volume fraction on the volume-based mean diameter $d_{43}$ : experimental data (experiments 4, 9, 10, 11 and 12 in Tab. 3) vs model predictions 
(a)

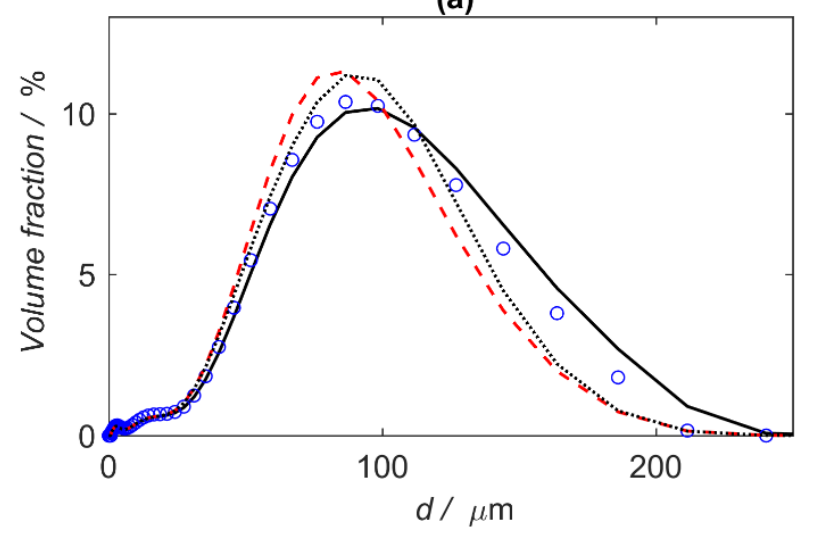

(b)

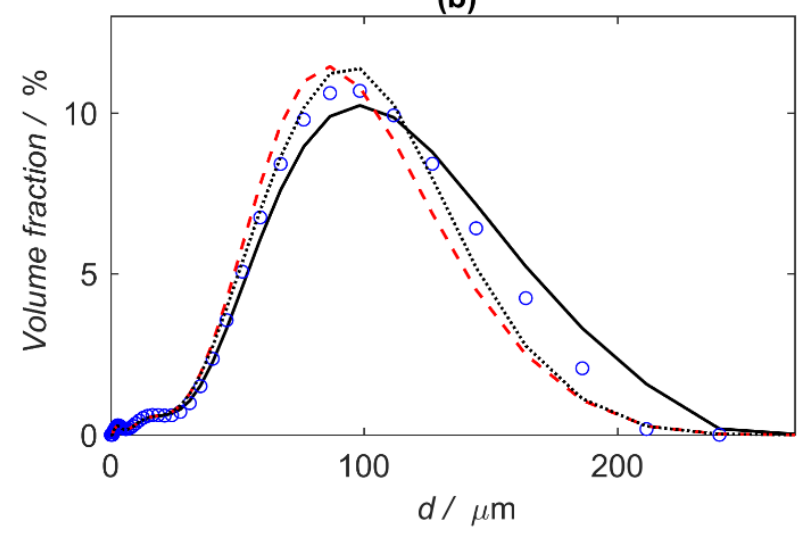

(c)

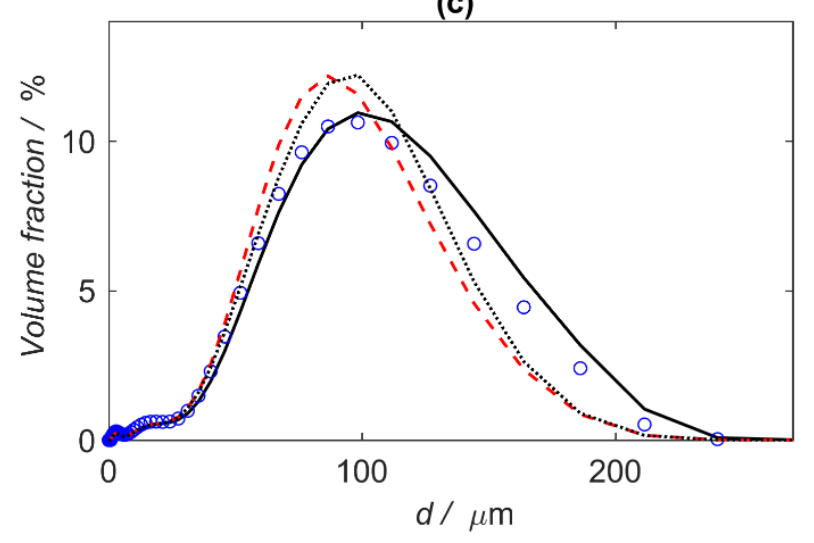

(d)

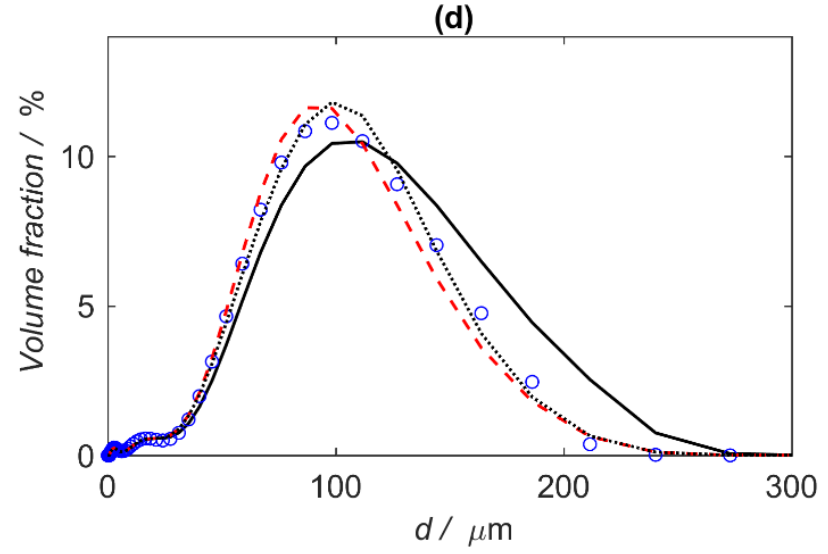

Fig. 7: Effect of the dispersed phase fraction on the DSD: (inlet: solid line, outlet: circles) vs model predictions (dashed line: Alopaeus model, dotted line: modified Coulaloglou model): (a) 2\%, (b) 3\%, (c) $4 \%$ and (d) $5 \%$ 


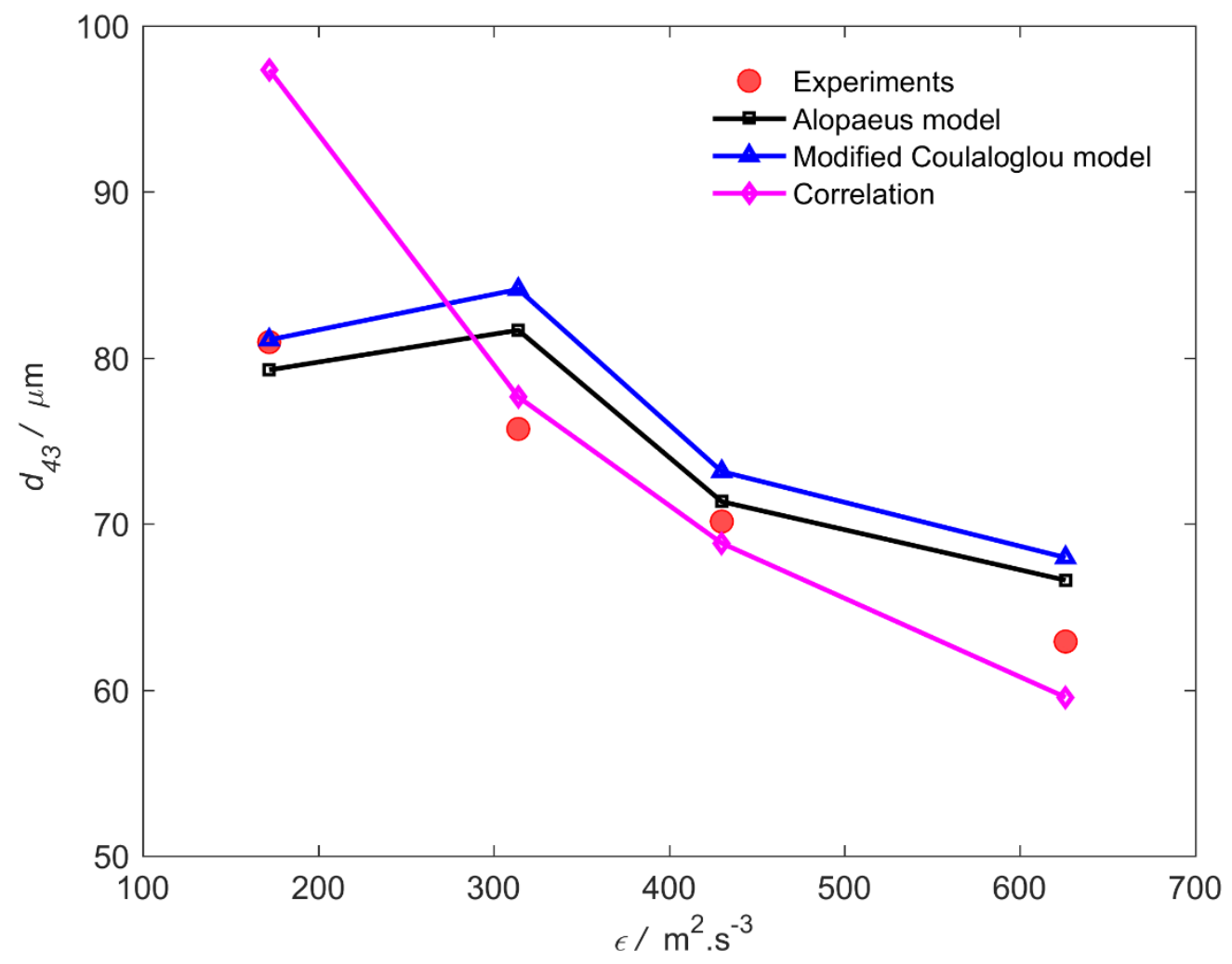

Fig. 8: effect of the volume-average turbulent energy dissipation rate on the volume-based mean diameter $\mathrm{d}_{43}$ : experimental data (experiments $4,13,14$ and 15 in Tab. 3 ) vs model predictions 
(a)

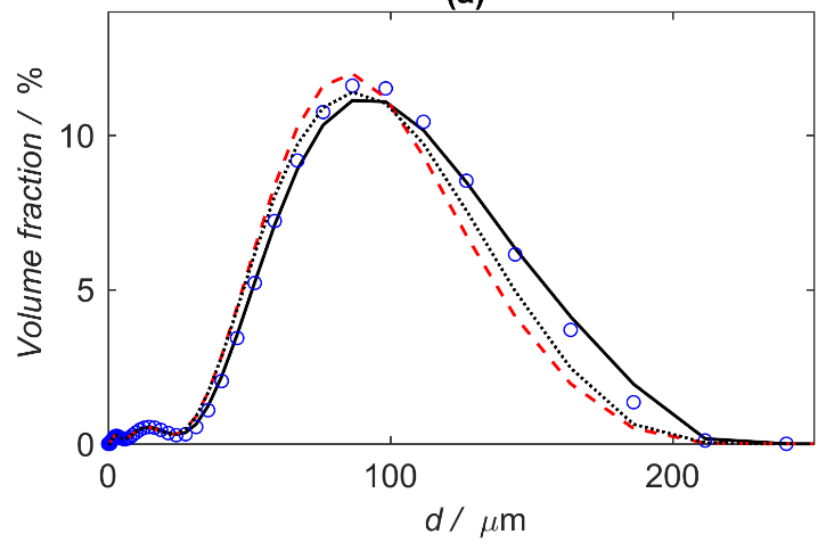

(b)

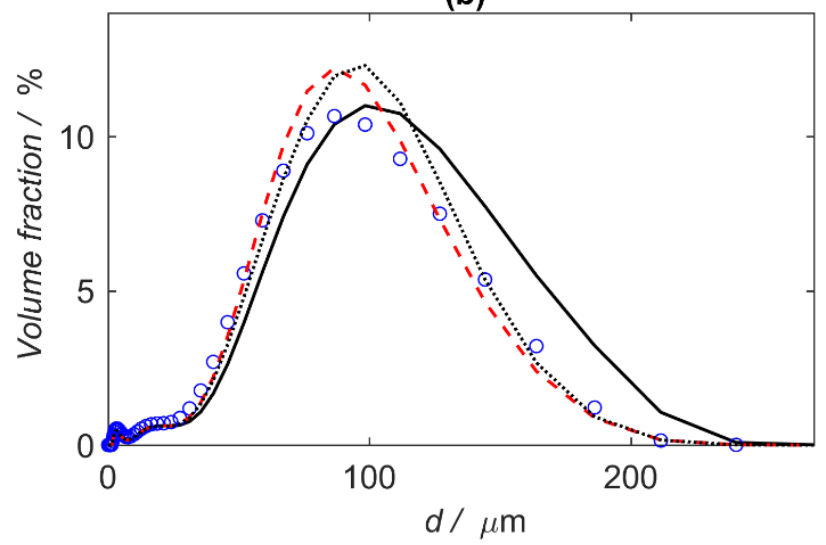

(c)

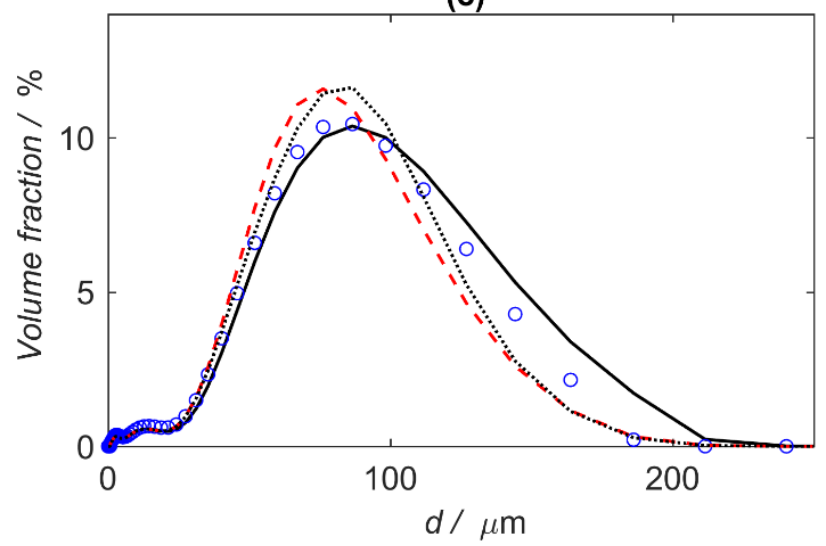

(d)

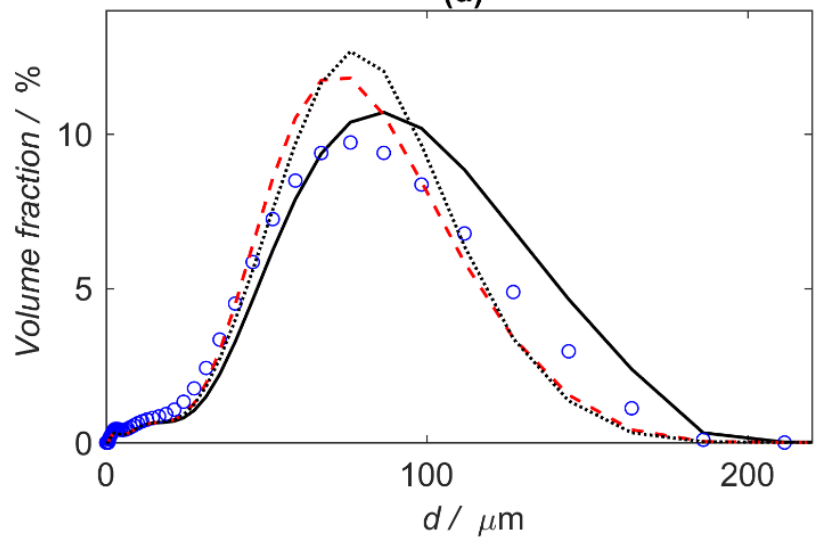

Fig. 9: Effect of the volume-average turbulent energy dissipation rate on the DSD: (inlet: solid line, outlet: circles) vs model predictions (dashed line: Alopaeus model, dotted line: modified Coulaloglou model): (a) $172 \mathrm{~m}^{2} \cdot \mathrm{s}^{-3}$, (b) $314 \mathrm{~m}^{2} \cdot \mathrm{s}^{-3}$, (c) $430 \mathrm{~m}^{2} \cdot \mathrm{s}^{-3}$ and (d) $626 \mathrm{~m}^{2} \cdot \mathrm{s}^{-3}$ 


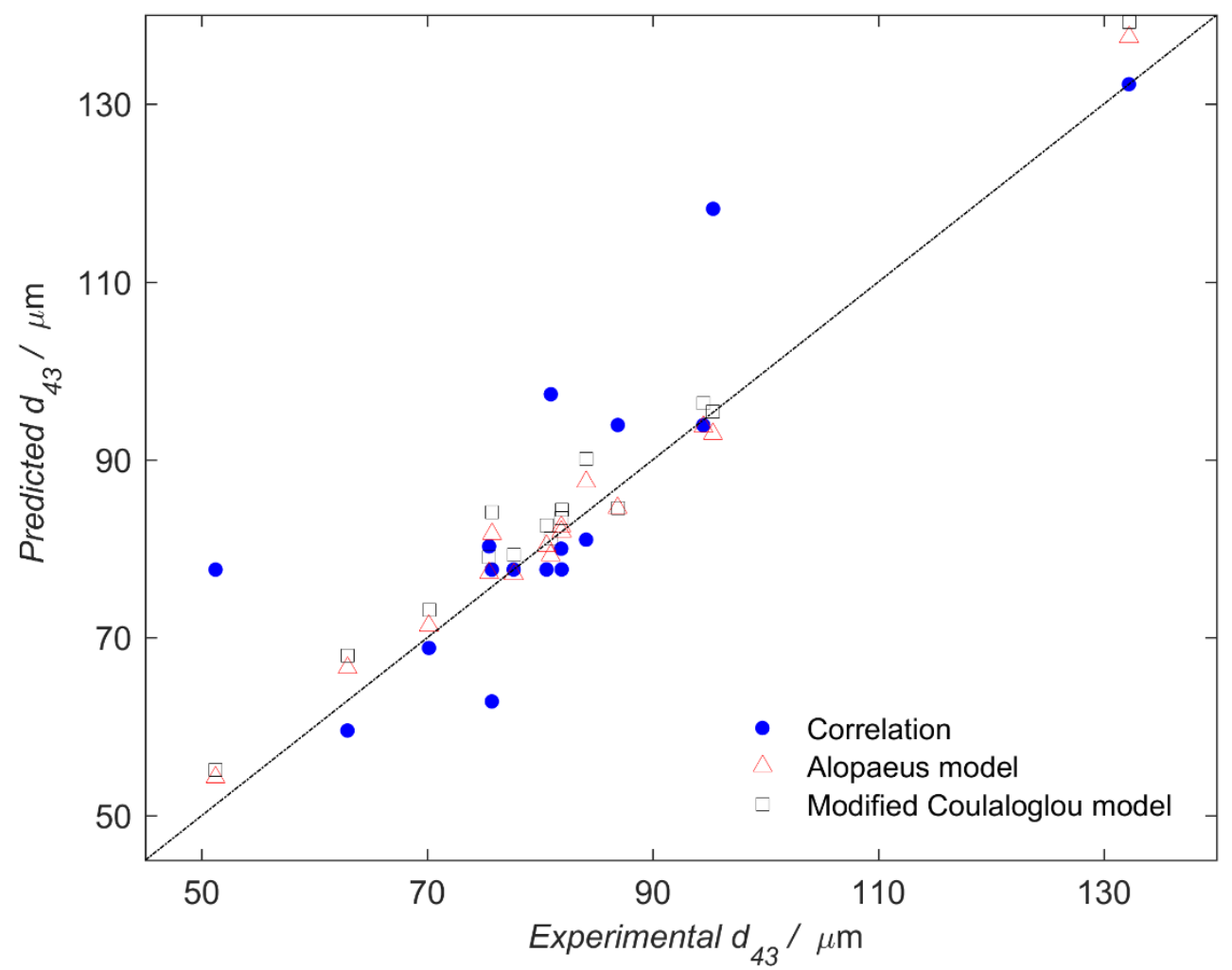

Fig. 10 


\section{Table of contents section}

A correlation and a population balance model are investigated for the prediction of droplet breakage during a continuous emulsification process using $\mathrm{SMX}+$ static mixers. The predictability of the two approaches is validated against experimental data obtained in different conditions. The transient correlation allows the prediction of the droplet mean diameter while the population balance model tracks the time evolution of the droplet size distribution between the inlet and the outlet of the mixing elements. 


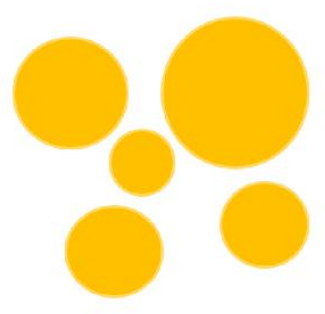

Inlet DSD
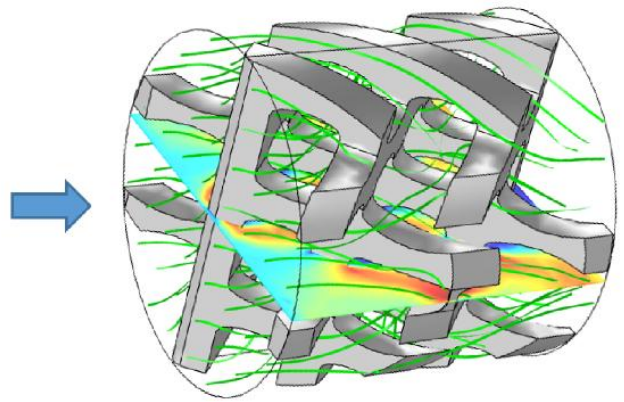

SMX+ mixing element

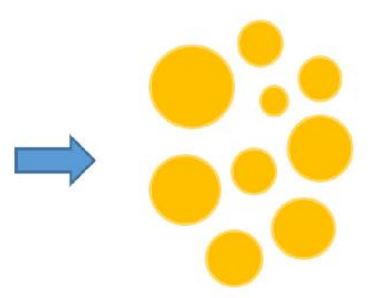

Outlet DSD 